\title{
Organ microenvironment affects growth and metastasis of hepatocellular carcinoma via the TGF- $\beta$ /Smad pathway in mice
}

\author{
GUOCAI LI ${ }^{1,2}$, LUNXIU QIN ${ }^{1}$, QINGHAI YE ${ }^{1}$, QIONGZHU DONG ${ }^{1}$, NING REN $^{1}$ and HULIANG JIA ${ }^{1}$ \\ ${ }^{1}$ Liver Cancer Institute, Zhongshan Hospital, Fudan University, Shanghai 200032; \\ ${ }^{2}$ Gaoxin Hospital, Xi'an Jiaotong University, Xi'an, Shanxi, P.R. China
}

Received August 13, 2012; Accepted October 9, 2012

DOI: 10.3892/etm.2012.752

\begin{abstract}
The interaction between cancer and the organ microenvironment is complex, and the transforming growth factor- $\beta$ (TGF- $\beta$ )/Smad pathway plays an important role in this interaction. However, the role of the organ microenvironment in hepatocellular carcinoma (HCC) is not well understood. To evaluate the effect of the organ microenvironment and the role of the TGF- $\beta /$ Smad pathway, MHCC $97-\mathrm{H}$ cells were inoculated subcutaneously into nude mice and the resulting MHCC97-H subcutaneous tumor tissues were implanted into the livers of the mice. We found a higher tumor weight and less pulmonary metastasis for the cancers in liver sites than for those in subcutaneous sites; the TGF- $\beta 1$ levels were significantly different between the tumor models and correlated with tumor metastasis. Our results suggest that the organ microenvironment affects the growth and invasion of liver cancer cells. The TGF- $\beta / \mathrm{Smad}$ pathway is significant in the interaction between HCC and its microenvironment and affects the progression of $\mathrm{HCC}$.
\end{abstract}

\section{Introduction}

Hepatocellular carcinoma (HCC) is one of the most common types of cancer in the world and a significant cause of mortality in sub-Saharan Africa and Eastern Asia (1). The overall five-year survival rate following resection has remained as low as $35-50 \%$ (2-4). The extremely poor prognosis of HCC is largely the result of a high rate of recurrence following surgery and of metastasis $(5,6)$. Exploring the mechanisms involved in the process of $\mathrm{HCC}$ metastasis is vital as it may provide new therapeutic targets for HCC and is likely to be useful in further improving the long-term survival of patients with HCC (7).

It is well documented that the specific organ microenvironment not only affects the proliferation, angiogenesis and invasion of cancer but also influences the expression of metas-

Correspondence to: Professor Lunxiu Qin, Liver Cancer Institute, Zhongshan Hospital, Fudan University, 180 FengLin Road, Shanghai 200032, P.R. China

E-mail:1x_qin@yahoo.com.cn

Key words: hepatocellular carcinoma, metastasis, transforming growth factor- $\beta$, organ microenvironment tasis-regulating genes $(8,9)$. Malignant cells in solid tumors communicate with the microenvironment via a complex network of extracellular signals, which includes a large number of cytokines (10). Therefore, investigation of the role of these cytokines in the interaction between the organ microenvironment and the tumor may aid the revelation of the mechanism of tumor metastasis. Transforming growth factor- $\beta$ (TGF- $\beta$ ) is a known regulator of epithelial cells and of autonomous tumor initiation, progression and metastasis (11-13). Components of the TGF- $\beta /$ Smad pathway are considered to be major tumor suppressor genes; the absence or malfunction of the genes is believed to lead to loss of growth regulation. Previous studies have indicated that TGF- $\beta$ is significantly involved in the interactions between cancer cells and the tumor microenvironment. Specifically, the loss of TGF- $\beta$ signaling in stromal components may result in an 'activated' microenvironment that supports and initiates the transformation of adjacent epithelial cells (14). In HCC, TGF- $\beta$ is a useful serological marker for the early detection of cancer (15) and plays a dual role in the progression of $\mathrm{HCC}$. TGF- $\beta$ is able to stimulate non-invasive HCC cells to acquire invasive phenotypes (16) and also induces in vitro apoptosis of hepatoma cells (17).

However, little is known regarding the interaction between the organ environment and HCC. Moreover, the role of TGF- $\beta /$ Smad in the course of HCC has yet to be elucidated. In the current study, we demonstrate that the organ microenvironment regulates the growth and invasion of liver cancer cells via TGF- $\beta /$ Smad.

\section{Materials and methods}

Cell lines and culture. The MHCC97-H cell line was established from human HCC cells in the Live Cancer Institute of Fudan University (Shanghai, China) $(18,19)$. The cells were cultured in high glucose Dulbecco's modified Eagle's medium (H-DMEM; Gibco-BRL, Carlsbad, CA, USA) and supplemented with $10 \%$ fetal calf serum (Gibco-BRL) at $37^{\circ} \mathrm{C}$ in a humidified incubator containing $5 \% \mathrm{CO}_{2}$.

Establishment of animal models of HCC. BALB/c nude mice, average weight $25 \mathrm{~g}$, were used in this experiment. MHCC97-H models were established by inoculating 6x10 ${ }^{6} \mathrm{MHCC} 97-\mathrm{H}$ cells subcutaneously into the right sides of the backs of the nude mice $(n=26)$. Xenograft models were established $(n=17)$ via 
Table I. Tumor weight and pulmonary metastasis rate in two models of hepatocellular carcinoma.

\begin{tabular}{lccccc}
\hline Model & No. of cases & $\begin{array}{c}\text { Tumor weight }(\mathrm{g}) \\
(\text { mean } \pm \text { SD) }\end{array}$ & $\begin{array}{c}\text { Metastatic rate, } \\
\%(\mathrm{n} / \text { total })\end{array}$ & $\begin{array}{c}\text { No. of metastatic foci } \\
(\text { mean } \pm \text { SD) }\end{array}$ & $\begin{array}{c}\text { No. of metastatic cells } \\
(\mathrm{mean} \pm \mathrm{SD})\end{array}$ \\
\hline MHCC97-H & 26 & $1.83 \pm 0.75$ & $69.2(18 / 26)$ & $4.72 \pm 5.50$ & $119.11 \pm 185.92$ \\
Xenograft & 17 & $2.89 \pm 0.84^{\mathrm{a}}$ & $64.7(11 / 17)$ & $2.27 \pm 1.01$ & $85.18 \pm 79.96^{\mathrm{b}}$ \\
\hline
\end{tabular}

$\mathrm{SD}$, standard deviation; ${ }^{\mathrm{P}}<0.01$, compared with the MHCC97-H group; ${ }^{\mathrm{b}} \mathrm{P}=0.08$, compared with MHCC $97-\mathrm{H}$ group.

orthotopic implantation of MHCC97-H subcutaneous tumor tissues (volume $\sim 2 \times 2 \times 1 \mathrm{~mm}^{3}$ ) into the livers of the mice as previously reported (20). These experiments were approved by the Shanghai Medical Experimental Animal Care Commission.

Collection of samples and analysis of pulmonary metastasis. After feeding for 35 days, the animals were sacrificed. The tumor tissues were removed and weighed. The lungs were removed, fixed in paraformalin and embedded in paraffin. Each sample was sliced into 20 sections, each $5 \mu \mathrm{m}$ in thickness with $50-\mu \mathrm{m}$ intervals between successive sections. After staining with hematoxylin and eosin (H\&E), the sections were independently observed under a microscope by two pathologists to evaluate pulmonary metastasis.

RNA extraction and real-time PCR. The total RNA of the tumor tissues was extracted using the TRIzol reagent (Invitrogen Life Technologies, Carlsbad, CA, USA) according to the instructions of the product. Using SYBR-Green mix (Toyobo Co., Ltd., Osaka, Japan), real-time RT-PCR analysis was performed to identify the expression levels of TGF- $\beta$, Smad2 and Smad7. The primers were designed by software (Primer Premier 5.0) as follow: TGF- $\beta$ sense, 5'-GGC GATACCTCAGCAACCG-3' and antisense, 5'-CTAAGG CGAAAGCCCTCAAT-3'; Smad2 sense, 5'-TACTACTCT TTCCCCTGT-3' and antisense, 5'-TTCTTGTCATTTCTA CCG-3'; Smad7 sense, 5'-CAACCGCAGCAGTTACCC-3' and antisense, 5'-CGAAAGCCTTGATGGAGA-3'; and $\beta$-actin sense, 5'-TCGTGCGTGACATTAAGGAG-3' and antisense, 5'-ATGCCAGGGTACATGGTAAT-3'. The amplification conditions were: $95^{\circ} \mathrm{C}$ for $9 \mathrm{~min}$, followed by 45 cycles of $95^{\circ} \mathrm{C}$ for $30 \mathrm{sec}, 57^{\circ} \mathrm{C}$ for $30 \mathrm{sec}$ and $72^{\circ} \mathrm{C}$ for $15 \mathrm{sec}$, followed by an extension at $72^{\circ} \mathrm{C}$ for $5 \mathrm{~min}$. $\beta$-actin was used as a control for the presence of amplifiable cDNA. The mRNA expression level was assessed by $2^{-\Delta \Delta \mathrm{Ct}}$. In brief, the $\mathrm{Ct}$ value for the target gene was subtracted from the $\mathrm{Ct}$ value of $\beta$-actin to yield a $\Delta \mathrm{Ct}$ value. The average $\Delta \mathrm{Ct}$ was calculated for the control group and this value was subtracted from the $\Delta \mathrm{Ct}$ of all other samples (including the control group). This resulted in a $\Delta \Delta \mathrm{Ct}$ value for all samples which was then used to calculate the fold-induction of mRNA expression of the target gene using the formula $2^{-\Delta \Delta C t}$, as recommended by the manufacturer (Bio-Rad, Hercules, CA, USA). In the current study, MHCC97-H model samples were used as the control.

Protein extraction and western blot analysis. Sections of frozen tumor samples ( $\mathrm{n}=14)$ were lysed in RIPA buffer $(50 \mathrm{mM}$ Tris- $\mathrm{HCl} \mathrm{pH} 7.5 ; 150 \mathrm{mM} \mathrm{NaCl} ; 0.5 \%$ NaDOC; $1 \%$ NP-40; and $0.1 \%$ SDS) with protease inhibitors. Protein was extracted by spinning in a microcentrifuge for $30 \mathrm{~min}$. Protein concentrations were determined using the Bradford reagent. Equal amounts of each sample $(20 \mu \mathrm{l})$ and $10 \mu \mathrm{l}$ markers were run on $10 \%$ SDS-PAGE gels and electro-transferred onto PVDF membranes using the Mini-Genie blotting system (Bio-Rad). The membranes were incubated with primary antibody, mouse anti-human TGF- $\beta 1$ antibody (Chemicon, Temecula, CA, USA; 1:1000 diluted), mouse anti-human $\beta$-actin antibody (Chemicon; 1:2000 dilution) and HRP-conjugated goat anti-mouse IgG secondary antibody (Sigma, St. Louis, MO, USA; 1:2000 dilution), The membranes were washed, incubated with $10 \mathrm{ml}$ LumiGLO and exposed to film.

Immunohistochemistry. Paraffin-embedded tumor tissues were sliced into $5 \mu \mathrm{m}$-thick sections and mounted on glass. The slides were deparaffinized and rehydrated over $10 \mathrm{~min}$ through a graded alcohol series to deionized water; $1 \%$ Antigen Unmasking solution (Vector Laboratories, Burlingame, CA, USA) and microwave treatment were used to enhance antigen retrieval. The slides were incubated with the specific TGF- $\beta 1$ primary antibody and with HRP-conjugated secondary antibody and then stained with DAB.

ELISA. The total protein of all tumor tissues was extracted as described in a previous section. TGF- $\beta 1$ protein levels in the tumors were determined using the Quantikine ELISA TGF- $\beta 1$ immunoassay kit (R\&D Systems, Minneapolis, MN, USA). The operational approach was according to the manufacturer's instructions.

Statistical analysis. Statistical analysis of the data was performed using SPSS 11.5 software (SPSS, Inc., Chicago, IL, USA). The correlation between TGF- $\beta /$ Smad and tumor weight was estimated using linear regression analysis and correlation coefficients were evaluated by the Student's t-test. Multiple covariance analysis was used for interaction between TGF- $\beta / \mathrm{Smad}$ and metastasis. All statistical tests were two-sided; $\mathrm{P}<0.05$ was considered to indicate a statistically significant result.

\section{Results}

Tumor weight and pulmonary metastasis in the animal models. The mean tumor weights ( $\mathrm{g}$ ) in the MHCC9-H and xenograft models were $1.83 \pm 0.75$ and $2.89 \pm 0.84$, respectively $(\mathrm{P}<0.01)$. The pulmonary metastatic rate and the number of metastatic foci in the MHCC97-H model were higher than those in the xenograft model (69.2 vs. $64.7 \%$; and $4.72 \pm 5.50$ vs. $2.27 \pm 1.01$, respectively) but the difference was not statistically significant, while the number of metastatic cells approximated a statisti- 
Table II. In vivo expression of TGF- $\beta 1 / \mathrm{Smad}$ mRNA in two mice models.

\begin{tabular}{|c|c|c|c|c|c|}
\hline \multirow[b]{2}{*}{ mRNA } & \multirow[b]{2}{*}{ Models } & \multirow[b]{2}{*}{$2^{-\Delta \Delta C \mathrm{Ct}}($ mean $\pm \mathrm{SD})$} & \multicolumn{2}{|c|}{$95 \% \mathrm{CI}$} & \multirow[b]{2}{*}{ P-value } \\
\hline & & & Lower bound & Higher bound & \\
\hline \multirow[t]{2}{*}{ TGF- $\beta 1$} & МНСС97 & $1.92 \pm 1.70$ & 1.23 & 2.61 & \multirow[t]{2}{*}{0.035} \\
\hline & Xenograft & $0.97 \pm 0.73$ & 0.59 & 1.35 & \\
\hline \multirow[t]{2}{*}{ Smad2 } & MHCC97 & $1.17 \pm 1.09$ & 0.73 & 1.61 & \multirow[t]{2}{*}{0.89} \\
\hline & Xenograft & $1.13 \pm 0.31$ & 0.98 & 1.29 & \\
\hline \multirow[t]{2}{*}{ Smad7 } & MHCC97 & $1.46 \pm 0.97$ & 1.07 & 1.85 & \multirow[t]{2}{*}{0.17} \\
\hline & Xenograft & $1.10 \pm 0.52$ & 0.83 & 1.37 & \\
\hline
\end{tabular}

Student's t-test was used to assess the statistical significance of differences between two groups. TGF- $\beta 1$, transforming growth factor- $\beta 1$; 95\% CI, 95\% confidence interval for mean; SD, standard deviation.

A

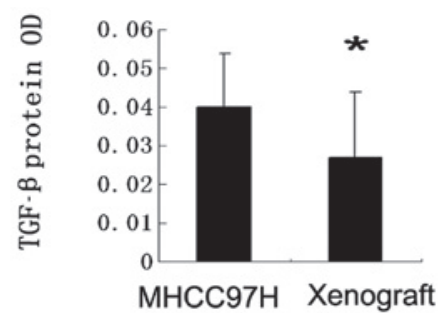

B

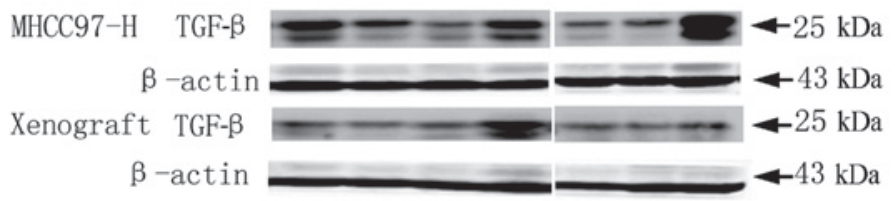

C

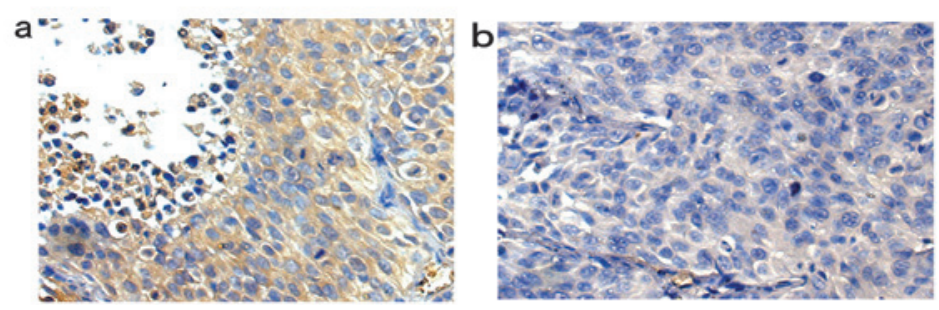

Figure 1. TGF- $\beta$ protein levels in two animal models. (A) TGF- $\beta$ protein levels in the MHCC97-H model were higher than in the xenograft model by ELISA, ${ }^{*} \mathrm{P}<0.05$. (B) TGF- $\beta$ protein levels in the MHCC $97-\mathrm{H}$ model were higher than in the xenograft model by western blot analysis. (C) The expression of TGF- $\beta 1$ in (a) the MHCC97-H model and (b) the xenograft model by immunohistochemical staining. The brown-yellow color is positive staining (x20 objective field). TGF- $\beta 1$, transforming growth factor- $\beta 1$.

cally significant difference $(119.11 \pm 185.92$ vs. $85.18 \pm 79.96$, respectively, $\mathrm{P}=0.08$; Table I).

Organ microenvironment may affect the expression of TGF- $\beta 1$ and Smad. After implanting the MHCC97-H subcutaneous tumor into the mouse liver, the mRNA levels of TGF- $\beta 1$ were significantly decreased $(1.92 \pm 1.70$ vs. $0.97 \pm 0.73 ; \mathrm{P}=0.035)$. However, the Smad2 and Smad7 mRNA levels in the MHCC97-H model were not statistically different from those in the xenograft model (Table II). The protein levels of TGF- $\beta 1$ in the MHCC97-H model mice were revealed to be higher than those in the xenograft model mice by ELISA with OD values of $0.04 \pm 0.01$ and $0.03 \pm 0.01$, respectively, $(\mathrm{P}=0.003$; Fig. $1 \mathrm{~A})$; similar results were obtained by western blotting (Fig. 1B) and immunohistochemical staining (Fig. 1C).
Expression of Smad7 correlated with tumor size. The mRNA levels of Smad7 linearly and positively correlated with those of Smad 2 by linear regression analysis. The correlation coefficient $R^{2}=0.15$, which has a statistical significance according to the Student's t-test ( $\mathrm{P}=0.005$; Fig. 2A). Moreover, Smad7 mRNA levels were linearly and negatively correlated with tumor weight $\left(\mathrm{R}^{2}=0.18, \mathrm{P}=0.005\right.$; Fig. $\left.2 \mathrm{~B}\right)$.

Expression of TGF- $\beta 1 \mathrm{mRNA}$ correlated with metastasis. We divided all the samples $(\mathrm{n}=43)$ into three groups according to the median metastatic cell number: non-metastatic, lower metastatic and higher metastatic groups. We identified that the higher metastatic group had a higher mean TGF- $\beta$ level than the non-metastatic and lower metastatic groups by multiple covariance analysis. The mean TGF- $\beta 1$ mRNA levels were 
Table III. Comparison of TGF- $\beta 1 / \mathrm{Smad}$ mRNA between metastatic and non-metastatic samples.

\begin{tabular}{|c|c|c|c|c|c|c|}
\hline \multirow[b]{2}{*}{ mRNA } & \multirow[b]{2}{*}{ Metastasis } & \multirow[b]{2}{*}{ No. } & \multirow[b]{2}{*}{$2^{-\Delta \Delta C t}($ mean $\pm S D)$} & \multicolumn{2}{|c|}{$95 \% \mathrm{CI}$} & \multirow[b]{2}{*}{ P-value } \\
\hline & & & & Lower bound & Higher bound & \\
\hline \multirow{3}{*}{ TGF- $\beta 1$} & None & 14 & $1.10 \pm 0.83$ & 0.61 & 1.58 & \multirow[t]{3}{*}{0.024} \\
\hline & Lower & 14 & $1.16 \pm 0.63$ & 0.79 & 1.53 & \\
\hline & Higher & 15 & $2.32 \pm 2.11$ & 1.16 & 3.49 & \\
\hline \multirow[t]{3}{*}{ Smad2 } & None & 14 & $1.23 \pm 1.35$ & 0.45 & 2.01 & \multirow[t]{3}{*}{0.65} \\
\hline & Lower & 14 & $0.97 \pm 0.55$ & 0.65 & 1.30 & \\
\hline & Higher & 15 & $1.25 \pm 0.47$ & 0.99 & 1.52 & \\
\hline \multirow[t]{3}{*}{ Smad7 } & None & 14 & $1.28 \pm 1.95$ & 0.59 & 1.97 & \multirow[t]{3}{*}{0.89} \\
\hline & Lower & 14 & $1.26 \pm 0.62$ & 0.91 & 1.62 & \\
\hline & Higher & 15 & $1.40 \pm 0.62$ & 1.06 & 1.75 & \\
\hline
\end{tabular}

Student's t-test was used to assess the statistical significance of differences between the two groups. TGF- $\beta 1$, transforming growth factor- $\beta 1$; 95\% CI, 95\% confidence interval for the mean; SD, standard deviation.

A

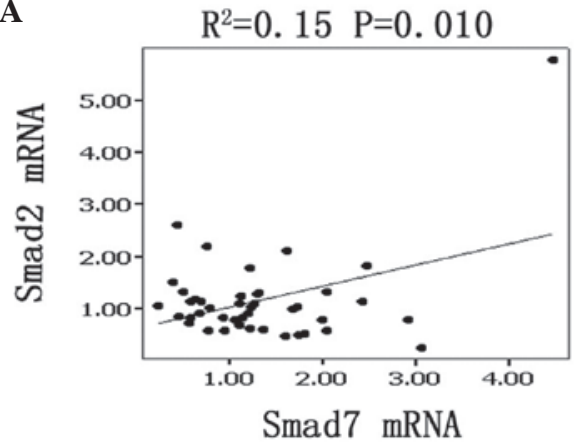

B

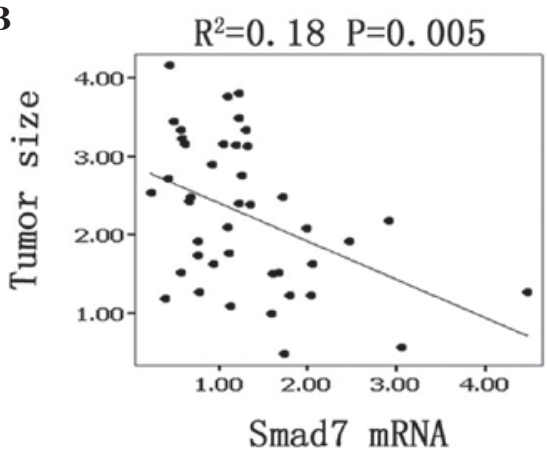

Figure 2. Correlation between Smad and tumor weight. (A) The expression of Smad2 and Smad7 was linearly correlated by regression analysis. (B) Smad7 expression was linearly correlated with tumor weight. Dots denote the samples. The lines are regression lines. R, correlation coefficient; P, P-value.

$2.32 \pm 2.11,1.10 \pm 0.83$ and $1.16 \pm 0.63$, respectively, $\mathrm{P}=0.024$ (Table III).

\section{Discussion}

Paget's 'seed and soil' hypothesis suggests that the interaction between tumor cells and target organ determines whether metastasis will occur (21). Metastasis depends on multiple interactions of cancer cells with host homeostatic mechanisms. In this present study, when the subcutaneous tumor tissues were transplanted into the liver, pulmonary metastasis was reduced. These results suggest that the organ microenvironment may alter the invasive potential of HCC.

We also found that the expression levels of TGF- $\beta 1$ in the MHCC97-H and xenograft models were statistically different. In addition, TGF- $\beta 1$ was highly expressed in the higher metastatic group and the expression of Smad7 negatively correlated with tumor size. These result indicate that the TGF- $\beta / \mathrm{Smad}$ pathway plays an important role in the interaction between $\mathrm{HCC}$ and the organ microenvironment and affects the progression of HCC. Similar results have been published for renal cancer, which demonstrate that the basic fibroblast growth factor (bFGF) levels of tumors implanted in kidney were
10-20 times higher than in subcutaneous tumors (22). Other studies have revealed that tumors growing in the stomach express more vascular endothelial cell growth factor (VEGF) than ectopically placed tumors and only the tumors in the stomach were able to undergo metastasis $(6,23)$.

It has been reported TGF- $\beta$ plays a dual role in the progression of tumors. During the early stages of tumor formation, TGF- $\beta$ acts as a tumor suppressor, inhibiting proliferation and inducing apoptosis of tumor cells. However, during the later stages of tumorigenesis, a number of tumor cells become unresponsive to the growth inhibitory functions of TGF- $\beta$ and become more motile and invasive (24). Our findings that the location of the tumor in the liver correlated with bigger size and lower metastasis are consistent with the dual role of TGF- $\beta 1$ following implantation and support this view.

The molecular mechanism for the downregulation of TGF- $\beta 1$ production in HCC in the liver remains unclear. With the exception of the delicate balance between TGF- $\beta$ and the tumor microenvironment (14), TGF- $\beta 1$ expression is affected by various growth factors secreted by normal and tumor cells. Signaling by TGF- $\beta$ family members occurs mainly through Smad proteins (25), and TGF- $\beta$ and Smad may cross-talk with other pathways $(26,27)$. Future studies are necessary to 
determine whether the expression levels of other factors are also modulated by the organ microenvironment.

A number of tumors have a selectivity for metastasis to specific organs; the precise cellular and molecular mechanisms involved are unknown. It has been reported that differences in tumor-secreted humoral factors, the upregulation of fibronectin and site-specific delivery of VEGFR $1^{+}$cells within target organs may promote metastatic spread in specific distant organs (28). Our results indicate that TGF- $\beta 1$ is significant in the preference for metastasis to the lung.

The results of the current study suggest that the organ environment affects the progression of HCC. For many years, all efforts to treat cancer have concentrated on the inhibition or destruction of tumor cells, but none of them have been able to alter the natural history of the disease $(8,29)$. Strategies to modulate the TGF- $\beta$ levels of the host microenvironment may provide a better approach for HCC treatment.

\section{Acknowledgements}

This study was supported in part by the China National Natural Science Foundation for Distinguished Young Scholars (30325041), the China National '863' R\&D High-Tech Key Project. The authors would like to thank Dr Qiong Xue, Dongmei Gao and Jun Chen for assistance with the animal experiments, Dr Ruixia Sun and Jie Chen for helpful suggestions concerning cell culture and Dr Haiying Zeng and Tengfang Zhu for performing the pathological experiments.

\section{References}

1. Parkin DM, Pisani P and Ferlay J: Global cancer statistics. CA Cancer J Clin 49: 33-64, 1999.

2. Kurokawa Y, Matoba R, Takemasa I, et al: Molecular-based prediction of early recurrence in hepatocellular carcinoma. J Hepatol 41: 284-291, 2004.

3. Lai EC, Fan ST, Lo CM, Chu KM, Liu CL and Wong J: Hepatic resection for hepatocellular carcinoma. An audit of 343 patients. Ann Surg 221: 291-298, 1995.

4. Ono T, Yamanoi A, Nazmy El Assal O, Kohno H and Nagasue N: Adjuvant chemotherapy after resection of hepatocellular carcinoma causes deterioration of long-term prognosis in cirrhotic patients: metaanalysis of three randomized controlled trials. Cancer 91: 2378-2385, 2001.

5. Genda T, Sakamoto M, Ichida T, Asakura H, Kojiro M, Narumiya $S$ and Hirohashi S: Cell motility mediated by rho and Rho-associated protein kinase plays a critical role in intrahepatic metastasis of human hepatocellular carcinoma. Hepatology 30 1027-1036, 1999

6. Ye QH, Qin LX, Forgues M, et al: Predicting hepatitis B virus-positive metastatic hepatocellular carcinomas using gene expression profiling and supervised machine learning. Nat Med 9: 416-423, 2003.

7. Qin LX and Tang ZY: Recent progress in predictive biomarkers for metastatic recurrence of human hepatocellular carcinoma: a review of the literature. J Cancer Res Clin Oncol 130: 497-513, 2004.

8. Fidler IJ: The organ microenvironment and cancer metastasis. Differentiation 70: 498-505, 2002.

9. Fidler IJ, Kim SJ and Langley RR: The role of the organ microenvironment in the biology and therapy of cancer metastasis. J Cell Biochem 101: 927-936, 2007.
10. Leek RD, Harris AL and Lewis CE: Cytokine networks in solid human tumors: regulation of angiogenesis. J Leukoc Biol 56: 423-435, 1994.

11. Giannelli G, Fransvea E, Marinosci F, et al: Transforming growth factor-beta1 triggers hepatocellular carcinoma invasiveness via alpha3betal integrin. Am J Pathol 161: 183-193, 2002.

12. Iyer S, Wang ZG, Akhtari M, Zhao W and Seth P: Targeting TGFbeta signaling for cancer therapy. Cancer Biol Ther 4: 261-266, 2005

13. Oft M, Peli J, Rudaz C, Schwarz H, Beug H and Reichmann E: TGFbetal and Ha-Ras collaborate in modulating the phenotypic plasticity and invasiveness of epithelial tumor cells. Genes Dev 10: 2462-2477, 1996.

14. Stover DG, Bierie B and Moses HL: A delicate balance: TGF-beta and the tumor microenvironment. J Cell Biochem 101: 851-861, 2007.

15. Song BC, Chung YH, Kim JA, et al: Transforming growth factor-beta1 as a useful serologic marker of small hepatocellular carcinoma. Cancer 94: 175-180, 2002.

16. Katabami K, Mizuno H, Sano R, et al: Transforming growth factor-beta1 upregulates transcription of alpha3 integrin gene in hepatocellular carcinoma cells via Ets-transcription factor-binding motif in the promoter region. Clin Exp Metastasis 22: 539-548, 2005.

17. Lin JK and Chou CK: In vitro apoptosis in the human hepatoma cell line induced by transforming growth factor beta 1 . Cancer Res 52: 385-388, 1992.

18. Li Y, Tang Y, Ye L, et al: Establishment of a hepatocellular carcinoma cell line with unique metastatic characteristics through in vivo selection and screening for metastasis-related genes through cDNA microarray. J Cancer Res Clin Oncol 129: 43-51, 2003 .

19. Li Y, Tang ZY, Ye SL, et al: Establishment of cell clones with different metastatic potential from the metastatic hepatocellular carcinoma cell line MHCC97. World J Gastroenterol 7: 630-636, 2001.

20. Zhou J, Tang ZY, Fan J, et al: Capecitabine inhibits postoperative recurrence and metastasis after liver cancer resection in nude mice with relation to the expression of platelet-derived endothelial cell growth factor. Clin Cancer Res 9: 6030-6037, 2003.

21. Paget $\mathrm{S}$ : The distribution of secondary growths in cancer of the breast. 1889. Cancer Metastasis Rev 8: 98-101, 1989.

22. Singh RK, Bucana CD, Gutman M, Fan D, Wilson MR and Fidler IJ: Organ site-dependent expression of basic fibroblast growth factor in human renal cell carcinoma cells. Am J Pathol 145: 365-374, 1994.

23. Takahashi Y, Mai M, Wilson MR, Kitadai Y, Bucana C and Ellis L: Site-dependent expression of vascular endothelial growth factor, angiogenesis and proliferation in human gastric carcinoma. Int J Oncol 8: 701-705, 1996.

24. Welm AL: TGFbeta primes breast tumor cells for metastasis. Cell 133: 27-28, 2008

25. Itoh S, Itoh F, Goumans MJ and Ten Dijke P: Signaling of transforming growth factor-b family members through Smad proteins. Eur J Biochem 267: 6954-6967, 2000.

26. Kwak HJ, Park MJ, Cho H, et al: Transforming growth factor-betal induces tissue inhibitor of metalloproteinase-1 expression via activation of extracellular signal-regulated kinase and Spl in human fibrosarcoma cells. Mol Cancer Res 4: 209-220, 2006.

27. Watanabe H, de Caestecker MP and Yamada Y: Transcriptional cross-talk between Smad, ERK1/2, and p38 mitogen-activated protein kinase pathways regulates transforming growth factorbeta-induced aggrecan gene expression in chondrogenic ATDC5 cells. J Biol Chem 276: 14466-14473, 2001.

28. Kaplan RN, Riba RD, Zacharoulis S, et al: VEGFR1-positive haematopoietic bone marrow progenitors initiate the pre-metastatic niche. Nature 438: 820-827, 2005.

29. Loberg RD, Bradley DA, Tomlins SA, Chinnaiyan AM and Pienta KJ: The lethal phenotype of cancer: the molecular basis of death due to malignancy. CA Cancer J Clin 57: 225-241, 2007. 